BELTRÁN, Ramón. "Estándares de prueba y su aplicación sobre el elemento material de la prisión preventiva en Chile".

Polít. crim. Vol. 7, No 14 (Diciembre 2012), Art. 6, pp. 454 - 479.

[http://www.politicacriminal.cl/Vol_07/n_14/Vol7N14A6.pdf]

\title{
Estándares de prueba y su aplicación sobre el elemento material de la prisión preventiva en Chile*** Ramón Beltrán Calfurrapa**
}

\section{Resumen}

El presente artículo tiene por finalidad denotar el rol de los estándares de convicción en su vinculación con la prisión preventiva en Chile. Por tal motivo, abarcando las diversas implicancias que estos suponen, propone la adopción de un estándar especial, a fin de determinar la aceptabilidad de las aserciones fácticas efectuadas en relación al elemento material de la prisión preventiva.

\section{Palabras clave}

Estándares de prueba, prisión preventiva, prueba de los hechos.

\begin{abstract}
The present article seeks to denote the role of the standards of conviction in relation to pretrial custody in Chile. Hence, reviewing the diverse implications these standards imply, it proposes the adoption of a special standard, in order to determine the acceptability of the factual assertions regarding the material element of the pretrial custody.
\end{abstract}

\section{Key words}

Standards of proof, pretrial custody, proof of the facts.

\section{Introducción}

Para nadie a estas alturas puede resultar vana la necesidad de tomarse los hechos en serio. $\mathrm{Y}$ es que, no obstante estar durante mucho tiempo relegados casi a un segundo plano, los hechos y su determinación en sede jurisdiccional, poco a poco han alcanzado un desarrollo

\footnotetext{
** Agradezco los valiosos comentarios y aportes efectuados por los profesores Raúl Núñez Ojeda, Ramón García Odgers y Claudio Fuentes Maureira. Evidentemente todo error es de mi exclusiva responsabilidad.

** Abogado; Académico de Derecho Procesal en la Facultad de Ciencias Jurídicas de la Universidad de Atacama, Copiapó; Becario por la Comisión Nacional de Investigación Científica y Tecnológica (CONICYT) en el Programa de Doctorado en Derecho de la Pontificia Universidad Católica de Valparaíso. Correo electrónico: ramón.beltran@uda.cl
} 
BELTRÁN, Ramón. "Estándares de prueba y su aplicación sobre el elemento material de la prisión preventiva en Chile".

evidente gracias a la comprensión de que el razonamiento judicial abarque no sólo cuestiones de Derecho, sino también cuestiones de hecho. ${ }^{1}$

La tarea a este respecto sin embargo no ha sido fácil. Asumiendo que la prueba de las aserciones fácticas no es en realidad una actividad solamente cognoscitiva, sino también resultado de una conclusión más o menos probable, cuya aceptación es un acto práctico; se ha tenido que demostrar que la convicción psicológica es una cuestión subjetiva que varía de persona en persona y, con frecuencia, en la misma persona de tiempo en tiempo; que no es posible predicar respecto de ella criterio epistemológico de corrección alguno; y que, por lo demás, no establece ningún rango de valoración y control aplicable al razonamiento probatorio. $^{2}$

Pilar fundamental en lo anterior, han sido los estándares de prueba. Con ellos, se han tratado de introducir pautas de suficiencia en la determinación factual que, aunque no en plena certeza, permiten lograr la aceptabilidad -en términos de probabilidad- de los diversos enunciados de hecho establecidos en sede adjudicativa. En materia procesal penal, a este respecto, conocido es el estándar de la duda razonable. Con él, no obstante sus merecidas críticas, en el fondo lo que se ha consagrado es el deber no sólo de respetar la presunción de inocencia -considerada en este estadio como regla de juicio- sino también el deber motivar la questio facti respecto de las diversas hipótesis explicativas vertidas en el juicio penal.

Sin embargo, si nos detenemos en la particularidad, es fácil advertir que dicho baremo, por sus características especiales, no puede ni debe ser aplicado a todas las materias que lo procesal penal supone. Por tal motivo, evidenciando la ausencia de estándares con un ámbito general de aplicación, el presente artículo pretende centrar su atención en una forma precisa de control factual respecto a un tipo concreto de resolución judicial: la que se pronuncia en torno al elemento material de la prisión preventiva.

En tal sentido, lo que se intentará es tratar de desarrollar una propuesta especial de estándar de prueba que, aunque inferior a la duda razonable y superior a la prueba prevalente, permitiría, en términos abstractos, la superación de la actual forma de determinar la suficiencia argumentativa respecto de la hipótesis de existencia y participación punibles, exigidas como requisito material en la procedencia de la prisión preventiva.

Para desarrollar lo anterior y tratar superar, en la medida de lo posible, los eventuales problemas asociados a la visión de los estándares de prueba tradicionales, se efectuará una breve explicación acerca de los mismos y, por sus imbricaciones en esta área, se abordará de manera especial el estándar de la duda razonable; luego, ya en el contexto de la prisión preventiva y su elemento material, se precisaran las diversas formas de control que a su respecto se han establecido, y; por último, atendiendo a la falta de un criterio moderador, se intentará desarrollar la propuesta de estándar ya sugerida.

\footnotetext{
${ }^{1}$ Cfr. TWINING, William, "De nuevo, los hechos en serio", Revista Doxa $\mathrm{n}^{\mathrm{o}} 32$ (2009), pp. 317-340.

${ }^{2}$ Vid. MENDONÇA, Daniel, Interpretación y aplicación del Derecho, Almería: Editorial Universidad de Almería, 1997, pp. 74 y ss.
} 
Polít. crim. Vol. 7, No 14 (Diciembre 2012), Art. 6, pp. 454 - 479.

[http://www.politicacriminal.cl/Vol_07/n_14/Vol7N14A6.pdf]

\section{Los estándares de prueba y su desarrollo evolutivo.}

Hablar de los estándares de convicción es hablar de la prueba de los hechos. Durante muchos años en el contexto de la teoría general del Derecho se hizo hincapié en la necesidad de establecer pautas meridianamente racionales respecto del control en la determinación fáctica, sin que a su respecto se haya efectuado mayor elaboración.

La regla de oro en dicho inhóspito escenario, era concebir la apreciación de los hechos como una actividad psicológica de "convicción íntima del juez", 3 respecto de la cual era no era posible esperar razonabilidad de ninguna especie. ${ }^{4}$ Así, la consideración de hecho probado era sinónimo de estado mental de convencimiento del iudex, lo que asociado a su inmediación, en cuanto forma de acceder a la información y formarse una impresión global del asunto, hacia inoficioso cualquier intento de justificación en torno a un razonamiento meridianamente articulado. ${ }^{5}$

Las limitaciones de orden práctico frente a lo anterior, implicaron la pervivencia -incluso hasta hoy- de dos ideas marcadamente erráticas y decimonónicas: La primera, sustentada

\footnotetext{
${ }^{3}$ Nótese que el contexto en que se usa el término "intima convicción" no está asociado a "libre convicción", pues, éste último predica y participa de ser un sistema probatorio y no un estándar de prueba, es decir, se refiere a la libérrima apreciación del componente factico efectuada por el juez y no a la ausencia de reglas de prueba legal o tasada que predeterminen el resultado probatorio de forma vinculante para el juez.

${ }^{4}$ Hoy en día términos como racional, racionalidad, o razonabilidad, se han convertido en un lugar común en los análisis de las decisiones judiciales. El término racionalidad -dogmáticamente hablando- tiene una pluralidad de significados que pueden reconducirse a dos: racionalidad teórica y racionalidad práctica. La primera consiste en poner en obra los medios adecuados para maximizar la amplitud, precisión y seguridad de nuestras creencias, tanto acerca del mundo en general, como de ámbitos específicos. La segunda consiste en esclarecer nuestros fines y poner en práctica de decisión los medios adecuados para obtener aquellos. En este sentido, si bien el razonamiento judicial es una especie de razonamiento práctico, en la medida en que la finalidad es tomar una decisión, la racionalidad práctica presupone siempre algún tipo de racionalidad teórica. De este modo, no obstante estar implicados en la cuestión de las decisiones, todos los conceptos antes aludidos abarcan siempre a la racionalidad teórica y, particularmente, a la racionalidad metodológica, la cual, respecto de cada alternativa de solución, ha de ofrecer las mejores razones de apoyo en la decisión final que se adopta. Con mayor profundidad, Vid. ITURRIALDE, Victoria, "Justificación judicial: Validez material y razones", Isegoria: Revista de filosofia moral y política $\mathrm{n}^{\circ} 35$ (2006), pp. 207-220.

${ }^{5}$ Sabido es que la inmediación es una garantía de carácter instrumental destinada a hacer posible, a partir del contacto directo entre juez y partes, una valoración racional de los actos probatorios a fin que puedan ser racionalmente enjuiciados por terceros. Por el contrario, cuando la inmediación es usada como limitante para vetar el acceso al componente fáctico determinado por el juez en su sentencia, esta garantía deviene en coartada mitigatoria de razones explicativas y justificativas de lo factual. Como expone Andrés Ibáñez: "La manera de entender la práctica de la inmediación en el tratamiento de las pruebas personales ha sido peligrosamente contaminada por el modo irracionalista de concebir el principio de libre convicción. En efecto, entendido éste como forma de captación emocional o intuitiva de lo expresado por la prueba, como una suerte de contacto con lo inefable, la audición y valoración de las manifestaciones del imputado y de los testigos sólo podrían producirse en ese ámbito de apreciación de y de forma que hace imposible cualquier pretensión de racionalizar u objetivar tal proceso de obtención de conocimiento y la justificación de los resultados. La consecuencia es que - conforme a ese punto de vista - "lo visto y oído" por el juez en ese encuentro sublime con sus fuentes de información, a más de no ser(al menos en lo esencial) verbalizable y justificable, sería también de imposible fiscalización, por quien no hubiera participado, y en el mismo plano de proximidad, de la misma singular experiencia". ANDRÉS IBÁÑEZ, Perfecto, "Sobre el valor de la inmediación. (Una aproximación crítica)", Revista Jueces Para la Democracia nº 46 (2003), p. 58.
} 
BELTRÁN, Ramón. "Estándares de prueba y su aplicación sobre el elemento material de la prisión preventiva en Chile".

en la no posibilidad de control por vía casacional de las aserciones fácticas determinadas por el tribunal $a$ quo en su sentencia; ${ }^{6}$ y, la segunda, cimentada en la mantención de la distinción entre verdad formal y verdad material. ${ }^{7}$

Todo lo dicho, sin embargo, desde un plano dogmático es simplemente historia. Hoy en día la moderna tendencia racional-analítica ha superado con creces la vetusta tendencia psicológica o persuasiva del juicio de hecho. Así, la apreciación de la prueba ya no implica ni significa ausencia de sujeción a cualquier clase de regla; ni la inmediación implica ni significa pretexto para dar por entendida la suficiencia en la determinación factual. Lo que determina la realidad y suficiencia factual son criterios epistemológicos $-\mathrm{y}$ a veces incluso contra-epistemológicos- que, por un lado, designan el grado de apoyo empírico que los elementos de juicio aportados al proceso proporcionan a las hipótesis en conflicto y, por otro, precisan las pautas generales que permiten determinar si el apoyo inductivo aportado es o no suficiente para tener por probada la hipótesis de mayor grado. ${ }^{8}$

De este modo, las ideas matrices de la denominada posición racional-analítica del juicio de hecho, son a lo menos dos: La primera es simple y clara: la finalidad de la prueba en el proceso judicial es la averiguación de la verdad de lo ocurrido. ${ }^{9}$ Luego, no se trata de verdades absolutas sino sólo de verdades relativas, no en el sentido de adoptar una concepción subjetiva o relativa de la misma, sino en el sentido de que el conocimiento de la verdad es relativo al contexto en que aquél es realizado y a la cantidad y calidad de información disponible. ${ }^{10}$

\footnotetext{
${ }^{6}$ El planteamiento de esta cuestión no podía ser mejor expresado que en palabras de Taruffo cuando señala que "El verdadero problema es comprender qué sucede cuando el razonamiento del juez supera los confines de lo que convencionalmente se entiende como 'derecho', y de individualizar cuales son las garantías de racionalidad y de razonabilidad, de credibilidad y de aceptabilidad y de controlabilidad de aquellos numerosos aspectos de la decisión judicial que no están ni directa ni indirectamente controlados o determinados por el derecho". TARUFFO, Michele, "Senso comune, esperienza e scienza nel ragionamento del giudice", Rivista Trimestrale di Diritto e Procedura Civile n³ (2001) pp. 665-695.

7 A propósito de dicha distinción conviene aclarar que la verdad de los enunciados sobre hechos es completamente independiente de si estos se verifican contextualmente dentro del proceso o fuera de él, ya que estos dependen exclusivamente de la realidad en que se presenten. Por ello Carnelutti insistió en que la verdad formal: “(...) no es más que una metáfora, sin lugar a dudas; en realidad, es fácil observar que la verdad no puede ser más que una, de forma que la verdad formal o jurídica o bien coincide con la verdad material, y no es más que verdad, o diverge de ella, y no es más que una no-verdad (...)”. CARNELUTTI, Francesco, La prueba civil, Argentina: Ediciones Depalma, 1947, pp. 29-30.

${ }^{8}$ Cfr. ACCATINO, Daniela, "Forma y Sustancia en el Razonamiento Probatorio. El Alcance del Control sobre la Valoración de la Prueba a través del Recurso de Nulidad Penal", Revista de Derecho de la Pontificia Universidad Católica de Valparaíso no 32 (2009), pp. 347-362.

${ }^{9}$ Cfr. MORESO, Juan José, La teoría del derecho de Bentham, Barcelona: Editorial PPU, 1992, pp. 354 y ss.

${ }^{10}$ Como explica Ferrer Beltrán: "el proceso judicial puede ofrecer sustento únicamente a verdades aproximadas; la información disponible en el mismo acerca de los hechos a probar es deficiente, tanto por su fiabilidad relativa como por su carácter necesariamente incompleto." FERRER, Jordi, "El contexto de la decisión sobre los hechos probados en el Derecho", en: ORTEGA, Santiago (ed.), Proceso, prueba y estándar, Lima: ARA Editores, 2009, p.55.
} 
Polít. crim. Vol. 7, No 14 (Diciembre 2012), Art. 6, pp. 454 - 479.

[http://www.politicacriminal.cl/Vol_07/n_14/Vol7N14A6.pdf]

Un enunciado, por consiguiente:

"es verdadero o no verdadero: no puede ser «más o menos» verdadero. Lo que puede variar según las circunstancias es el grado de confirmación que se puede atribuir a un enunciado sobre la base de los conocimientos disponibles: podrá existir, por tanto, una mayor o menor aproximación a la verdad, de acuerdo al contexto y según las circunstancias". 11

La segunda idea, por su parte, supone el reconocimiento que aunque el proceso se oriente a la búsqueda de la verdad éste no puede ser su fin único. Así, el objetivo de buscar la verdad, cuando se es consciente de la falibilidad de los procedimientos usados para ello, se traduce de inmediato en el objetivo de minimizar el riesgo de error. ${ }^{12}$ De hecho, por ejemplo, en materia procesal penal, históricamente las sociedades occidentales han considerado mucho más grave y, por lo tanto, mucho más costoso, el error consistente en una condena falsa - que implica que personas inocentes sean privadas de su libertad-que una absolución falsa. ${ }^{13}$ Por tal motivo, como refleja la proporción de Blackstone: "en diez errores, preferimos que hasta nueve, consistan en absoluciones falsas, o lo que es lo mismo, que estamos dispuestos a tolerar sólo una condena falsa por cada diez errores que se cometan". 14

De este modo, al contrario de lo que generalmente se piensa, el proceso no se agota con la realización procedimental de actos dirigidos a legitimar formalmente la solución de la controversia. Adicional a ello, abonan aspectos epistemológicos con el fin de evaluar si los hechos que se dicen probados son o no validos para el descubrimiento de la verdad. Pero su función tampoco se agota ahí. El proceso es también configurado por cuestiones ideológicas que tienen repercusiones respecto a las diversas estrategias planteadas para minimizar el riesgo de error en la cuestión factual. Así, en todos los ordenamientos procesales existen pautas que influyen en la reglamentación probatoria y que, motivadas por cuestiones ideológicas, muchas veces implican la prevalencia de razones no epistémicas por sobre razones epistémicas. ${ }^{15}$ El caso emblemático de ello es precisamente la distribución del riesgo de error en los estándares de prueba, los cuales, en su construcción, no responden necesariamente razones epistemológicas. ${ }^{16}$

11 TARUFFO, Michele, Simplemente La Verdad. El juez y la construcción de los hechos. Trad. Daniela Accatino, Barcelona: Marcial Pons, 2010, p. 99.

12 Vid. BAYON, Juan Carlos, "Epistemología, moral y prueba de los hechos: hacia un enfoque no benthamiano", ponencia presentada en el XIV Congreso ítalo-español de Teoría del Derecho [disponible en internet: $\quad$ http://www.udg.edu/LinkClick.aspx?fileticket=fYVRM58p9Z4\%3D\&tabid=9724\&language=enUS], p. 4.

${ }^{13}$ Vid. LAUDAN, Larry, "Por qué un estándar de prueba subjetivo y ambiguo no es un estándar", Revista Doxa $\mathrm{n}^{\circ} 28$ (2005), pp. 96 y ss.

${ }^{14}$ AGUILERA, Edgar, "Crítica a la "convicción íntima" como estándar de prueba en materia penal”, Reforma Judicial, Revista Mexicana de Justicia no 12 (2008), pp. 5 y ss.

${ }^{15}$ Cfr. TARUFFO, Simplemente La Verdad, cit. nota ${ }^{\circ} 11$, p. 157.

${ }^{16}$ Se trata, por lo tanto, de elecciones ideológicas que influyen a su vez en orientaciones legislativas y sobre las cuales no es posible predicar criterio epistemológico directo en la determinación acerca de cuál sería el grado de probabilidad para que una hipótesis se tenga por probada. Como explica Bayon: "Si lo que en el fondo se quiere resaltar es que "la epistemología no puede determinar los estándares de prueba" (...) —lo que puede concederse sin problema alguno, dado que difícilmente podrían ser razones epistemológicas las que 
BELTRÁN, Ramón. "Estándares de prueba y su aplicación sobre el elemento material de la prisión preventiva en Chile".

Con todo, asumiendo las premisas antes aludidas, un enunciado fáctico será verdadero cuando a través de un procedimiento idóneo sea justificado por razones que permitan considerarlo como verdadero. Luego, dado que su determinación es sólo probabilística, la polisemia y pragmática asociada a sus usos, ha dado pie a dos grandes modelos destinados a determinar los grados de probabilidad sobre los cuales se ha de estimar respaldada una aserción de hecho. ${ }^{17}$

Uno es el modelo matemático-estadístico -también llamado Pascaliano o Bayesiano-, el cual sostiene la posibilidad de expresar numéricamente el grado de probabilidad respecto a la convicción alcanzada, midiendo "el impacto que, sobre la probabilidad subjetiva previa del hecho que se pretende probar, provoca la introducción de ulteriores elementos de prueba." 18 Otro es el modelo de confirmación o contrastación de hipótesis -también llamado Baconiano-, en donde el grado de convicción se mediría mediante su contrastación con la información existente sobre el hecho, es decir, no buscando la determinación cuantitativa de las clases de eventos, sino el "racionalizar la incertidumbre correspondiente a la hipótesis sobre un hecho, reconduciendo su grado de fundamentación al ámbito de los elementos de confirmación (o prueba)disponibles en relación con esa hipótesis". ${ }^{19}$

Sin perder lo ejes centrales de esta exposición, diremos que el modelo matemáticoestadístico no parecen calzar con la estructura dialéctica que exige un sistema adjudicativo en el Estado democrático de Derecho. En efecto, aunque útiles en teoría, en la praxis presentan como falencia central pues producen una sobrevaloración de la probabilidad inicial y una minusvaloración del peso que tienen las nuevas pruebas en el cálculo de la probabilidad final. ${ }^{20}$ Así, como sarcásticamente lo señalan algunos autores, ${ }^{21}$ mientras, por ejemplo, un cálculo de la esperanza de vida de la clase de conductores de 30 años es un principio bayesiano o estadístico, un cálculo de la esperanza de vida de Juan (un camionero, de corazón débil, montañista y con buen sentido del humor) es un principio Baconiano.

Sobre esta base y acogiendo el análisis del modelo de confirmación de hipótesis o Baconiano, diremos que tradicionalmente se han esbozado a su respecto dos subsistemas de

determinaran de qué forma debe distribuirse el riesgo del error- creo que bastaría con decir que lo que la epistemología no puede hacer es determinar cuál es el grado de probabilidad de que una hipótesis sea verdadera que resulta suficiente no para "aceptarla como verdadera", sino para "tenerla por probada". BAYON, "Epistemología, moral y prueba”, cit. nota n 12, p. 8.

${ }^{17}$ Es sabido que existen al menos tres conceptos distintos de probabilidad. La probabilidad como medida de creencia, que es aquella que puede asignarse a un evento que depende del grado en que un sujeto racional crea que puede ocurrir; la probabilidad como frecuencia relativa, que es aquella que puede asignarse a un evento que depende de la relación entre en número de casos favorables a ese evento y la cantidad de casos posibles; y la probabilidad como frecuencia de verdad, que es aquella que puede asignarse a una proposición que depende de la frecuencia relativa con que una clase de inferencia conduce, a partir de premisas verdaderas, a conclusiones verdaderas. Cfr. MENDONÇA, Daniel, Las claves del Derecho, Barcelona: Editorial Gedisa, 2008, p. 196.

${ }^{18}$ MENDONÇA, Las claves del Derecho, cit. nota $\mathrm{n}^{\circ} 17$, p. 22.

${ }^{19}$ TARUFFO, Michele, La prueba de los hechos. Trad. Jordi Ferrer Beltrán, Madrid: Trotta Editorial, 2009, p. 224.

${ }^{20}$ LAUDAN, "Por qué un estándar", cit. nota n 13 , pp. 98 y ss.

21 TWINING, William, "Rule-scepticism and Fact-scepticism in Bentham's Theory of Evidence", en: EL MISMO, Facts in Law, Wiesbaden: Franz Steiner, 1982, pp. 65-81. 
Polít. crim. Vol. 7, No 14 (Diciembre 2012), Art. 6, pp. 454 - 479.

[http://www.politicacriminal.cl/Vol_07/n_14/Vol7N14A6.pdf]

aplicación, distinguibles sólo en atención al grado o quantum de distribución de error predicable de cada uno de ellos.

El primero de ellos es el sistema de prevalencia o preponderancia (también llamado en el derecho Anglosajón como preponderance of evidence, preponderance of probability o greater weight of evidence). Según éste, una hipótesis fáctica resultará aceptable o probada cuando sea más probable o verosímil que cualquiera de las hipótesis alternativas sobre el mismo hecho. ${ }^{22}$ Su manifestación y utilización más concreta se verifica en materia procesal civil y, en palabras de Taruffo, ${ }^{23}$ sus premisas principales son: (a) Que se conciba la decisión del juez sobre los hechos como el resultado final de elecciones en torno a varias hipótesis posibles relativas a la reconstrucción de cada hecho de la causa; (b) Que estas elecciones se conciban como si fueran guiadas por criterios de racionalidad; (c) Que se considere racional la elección que toma como "verdadera" la hipótesis sobre hechos que resulta mejor fundada y justificada por las pruebas respecto a cualquier otra hipótesis; (d) Que se utilice, como clave de lectura del problema de la valoración de las pruebas, no un concepto genérico de probabilidad como mera no-certeza, sino un concepto específico de probabilidad como grado de confirmación de la veracidad de un enunciado, sobre la base de los elementos de confirmación disponibles. ${ }^{24}$

El segundo de ellos es el sistema de la duda razonable (también llamado en el common law como beyond any reasonable doubt). ${ }^{25}$ Según éste, una hipótesis fáctica resultará aceptada o probada cuando se cumpla con un grado particularmente alto de confirmación probatoria respecto de la culpabilidad del imputado. Así,

"se trata entonces que el juez penal pueda condenar al imputado solamente cuando se haya conseguido, a lo menos tendencialmente, la certeza de su culpabilidad. Mientras que el imputado tendrá que ser absuelto todas las veces que sobre su culpabilidad

\footnotetext{
${ }^{22}$ Sobre el tema, Vid. CLERMONT, Kevin; SHERWIN, Emily, "A comparative View of Standards of Proof", The American Journal of Comparative Law, vol. 50, $\mathrm{n}^{\circ} 2$ (2002) pp. 243-275. ENGEL, Christoph, "Preponderance of the Evidence Versus Intime Conviction: A Behavioral Perspective on a Conflict Between American and Continental European Law", Vermont Law Review, Vol. 33 (2009), pp. 435-467. HAMER, David, "The Civil Standard of Proof Uncertainty: Probability, Belief and Justice", The Sydney Law Review, vol. 16 (1994), pp. 506-536. WILLIAMS, C. R., "Burdens and Standards in Civil Litigation", The Sydney Law Review, vol. 25, nº 2 (2003), pp. 165-188.

${ }^{23}$ TARUFFO, Michele, "Conocimiento y criterios de la prueba judicial", en ORTEGA, Proceso, prueba y estándar, cit. nota $\mathrm{n}^{\mathrm{o}} 10, \mathrm{p} .43$.

${ }^{24}$ Para una visión amplia de los estándares de convicción en el proceso civil, Vid. FUENTES, Claudio. "Consideraciones en torno a la idea del estándar de convicción en el proceso civil" en: LETURIA, Francisco (ed.), Justicia civil y comercial: Una reforma ¿cercana?, Santiago: Ediciones Libertad y Desarrollo, 2011, pp. 173-205.

Sobre el tema, Vid. SHAPIRO, Barbara, Beyond reasonable doubt and probable cause: Historical perspectives on the anglo-american law of evidence, Berkeley: University of California Press, 1991. LAUDAN, Larry, "Is reasonable doubt reasonable?", Legal Theory, vol. 9 (2003), pp. 295-331. MULRINE, Thomas, "Reasonable doubt: how in the world it is defined?", American University International Law Review $\mathrm{n}^{\mathrm{o}} 12$ (1997), pp. 195-225. LILLQUIST, Erik, "Recasting Reasonable Doubt: Decision Theory and the Virtues of variability", U. C. Davis Law Review no 36 (2002) pp. 185 y ss.
} 


\section{BELTRÁN, Ramón. "Estándares de prueba y su aplicación sobre el elemento material de la prisión preventiva en Chile".}

resulte, así las pruebas estén a su cargo, una duda razonable sobre su eventual inocencia". ${ }^{26}$

Luego, siendo el análisis de éste estándar uno de los objetivos del presente artículo, pasaremos a detallar ciertas particularidades del mismo en especial al caso Chileno. ${ }^{27}$

\section{La duda razonable en el derecho procesal penal chileno.}

Sabido es que uno de los bastiones sobre los cuales descansa el proceso penal imperante en nuestro país, como resabio del principio democrático, es el llamado principio de culpabilidad. Éste, según algunos, ${ }^{28}$ resumiendo la exigencia complementaria de legalidad en el sentido de que no hay delito ni pena sin culpabilidad -nullum crimen nulla poena sine culpa- ${ }^{29}$ desempeñaría una función esencial no sólo como límite de la medida de la pena,

${ }^{26}$ TARUFFO, Michele, "Conocimiento científico y criterios de la prueba judicial", en: ORTEGA GOMERO, Santiago (ed.), Proceso, prueba y estándar. Lima: ARA Editores, 2009, pp. 43 y ss.

${ }^{27}$ En principio diremos que este estándar es utilizado en materia procesal penal y su historia encuentra enraizada por más de 200 años en el sistema del common law. En efecto, baste con hacer referencia a la enfatización efectuada por la Corte Suprema de los Estados Unidos en 1970 en el caso "In re Winship", respecto del cual se aclaró que su aplicación resulta exigida por la cláusula constitucional del debido proceso, para entender su relevancia e importancia. En dicha resolución se dejo constancia expresa que: "The requirement that guilt of a criminal charge be established by proof beyond a reasonable doubt dates at least from our early years as a Nation. The 'demand for a higher degree of persuasion in criminal cases was recurrently expressed from ancient times, (though) its crystallization into the formula 'beyond a reasonable doubt' seems to have occurred as late as 1798. It is now accepted in common law jurisdictions as the measure of persuasion by which the prosecution must convince the trier of all the essential elements of guilt. (...). Although virtually unanimous adherence to the reasonable-doubt standard in common-law jurisdictions may not conclusively establish it as a requirement of due process, such adherence does 'reflect a profound judgment about the way in which law should be enforced and justice administered.' "In Re Winship", 397 U.S. 358 (1970).

${ }^{28}$ A este respecto conviene señalar que nuestra doctrina se encuentra dividida entre quienes reconocen en la Ley Fundamental de 1980 una explícita consagración del "nulla poena sine culpa", y quienes son escépticos en esta materia. En tal sentido, Vid. KÜNSEMÜLLER, Carlos, "El Principio de Culpabilidad en el Derecho Penal Chileno", en: ARROYO, Luis; VERDUGO, Ignacio (Coords.), Homenaje al Dr. Marino Barbero Santos: "In memoriam", Vol. 1, Toledo: Ediciones de la Universidad Castilla-La Mancha / Ediciones Universidad Salamanca, 2001, pp. 1079-1098. SOTO, Miguel, "Una Jurisprudencia Histórica: Hacia el Reconocimiento del Principio de Culpabilidad en el Derecho Penal Chileno", Revista de Derecho de la Universidad Finis Terrae, t. III (1999), pp. 233 y ss. Sin perjuicio de lo dicho, según un sector de nuestra jurisprudencia, el principio de culpabilidad se encontraría retratado tanto en el artículo $19 \mathrm{~N}^{\circ} 3$ inciso 6 de la Constitución, como en diversos tratados internacionales, pues: "no hay pena sin culpabilidad, esto es, sólo la culpabilidad comprobada -y su contenido volitivo- por los medios de prueba legal, justifican la valoración o juicio de reproche (...) de tal forma que la pena no debe rebasar la medida de la culpabilidad (autor español José Cerezo Mir: El delito como acción culpable), o sea que la sanción penal no debe ser desproporcionada o exceder arbitrariamente el disvalor objetivo que contiene la conducta del agente". CORTE DE APELACIONES DE SAN MIGUEL. Fallo Causa Rol N ${ }^{\circ} 1200-2003$, de 24 de septiembre de 2003. De manera idéntica y del mismo tribunal, Vid. Fallo Causa Rol N 3361-2003, de 12 de mayo de 2004. Gaceta Jurídica $\mathrm{n}^{\circ} 289$ (2004), pp. 183 y ss.

${ }^{29}$ Sobre la relación entre culpabilidad y pena. Vid. KINDHÄUSER, Urs, "Retribución de culpabilidad y pena", en: KINDHÄUSER, Urs; MAÑALICH, Juan Pablo, Pena y culpabilidad en el Estado democrático de Derecho. Trad. Nuria Pastor, Buenos Aires: ARA Editores, 2011, pp. 147 y ss. 


\section{Polít. crim. Vol. 7, Nº 14 (Diciembre 2012), Art. 6, pp. 454 - 479. [http://www.politicacriminal.cl/Vol_07/n_14/Vol7N14A6.pdf]}

sino también en la exclusión de la responsabilidad. ${ }^{30}$ De este modo, consciente de ello, el actual Código Procesal Penal (en adelante "C.P.P.") efectúo una doble consideración a su respecto: En primer lugar, enfatizó que "ninguna persona será considerada culpable ni tratada como tal en tanto no fuere condenada por una sentencia firme" (Art. 2 C.P.P.); y, en segundo lugar, preceptuó que:

"nadie podrá ser condenado por delito sino cuando el tribunal que lo juzgare adquiriere, más allá de toda duda razonable, la convicción de que realmente se hubiere cometido el hecho punible objeto de la acusación y que en él hubiere correspondido al acusado una participación culpable y penada por la Ley. El tribunal formará su convicción sobre la base de la prueba producida durante el juicio oral. No se podrá condenar a una persona con el sólo mérito de su propia declaración" (Art. 340 del C.P.P).

Con dichas consideraciones, no hay dudas que la garantía de la presunción de inocencia en nuestro Derecho se vio notablemente robustecida. ${ }^{31}$ Así, no sólo paso a configurar una regla de tratamiento -en virtud de la cual el imputado tiene derecho a recibir la consideración y trato de no participe en la comisión de los hechos delictivos-; o una regla de probatoria -en cuya virtud se debe garantizar la existencia, rendición y valoración de toda prueba congruente en la concreción de derechos fundamentales-; sino también una regla de juicio. ${ }^{32}$ Ello supuso, desde una faz operativa, que el órgano jurisdiccional debe motivar y precisar, en la aceptabilidad adjudicativa de los hechos que configuran la quaestio facti de su sentencia, que al imputado le ha correspondido más allá de toda duda razonable una participación culpable y penada por la Ley. ${ }^{33}$

Una primera aproximación de lo expuesto, nos llevaría a pensar que con la incorporación de la presunción de inocencia como regla de juico y la duda razonable como fórmula de control factual, las consecuencias de la intime conviction psicológica en Chile -a lo menos en lo normativo- fueron atenuadas. Es decir, se neutralizaría por un lado lo expresado por el mensaje del actual Código Penal, el cual expresa que:

\footnotetext{
${ }^{30}$ Sobre el criterio retributivo de culpabilidad como orientación legitimadora de la pena en la jurisprudencia chilena, Vid. DURAN, Mario, "Justificación y legitimación político-criminal de la pena. Concepto, criterios y orientaciones en la actual jurisprudencia nacional", Política Criminal no 8 (2009), pp. 1-24.

31 En el caso norteamericano se ha sostenido que: "The standard provides concrete substance for the presumption of innocence-that bedrock axiomatic and elementary principle whose enforcement lies at the foundation of the administration of our criminal law". "In re Winship", 397 U.S. 358, (1970).

32 Sobre dicha distinción, Vid. FERNÁNDEZ, Mercedes, Prueba y Presunción de inocencia, Madrid: Iustel. Portal Derecho S.A., 2005, pp. 117-159. ANDRÉS IBAÑEZ, Perfecto, "Presunción de inocencia y prisión sin condena", Cuadernos de Derecho Judicial nº 18 (1996), pp. 13-46.

${ }^{33}$ Como explica Mercedes Fernández: "La función de la regla de juicio asume un papel relevante en un momento posterior, concretamente cuando tras la valoración de la prueba practicada con todas las garantías (esto es, cuando ha sido superada la presunción de inocencia desde el punto de vista de su función como regla probatoria), el resultado que de ella se deriva no es concluyente y, por lo tanto, impide que el órgano judicial resuelva conforme a él. En estos casos la duda - como consecuencia de una actividad probatoria de cargo insuficiente - debe resolverse a favor del acusado por aplicación de la presunción de inocencia. Sin embargo, como después se verá, la absolución en caso de duda se suele reconducir al campo de aplicación del principio in dubio pro reo, que, por otra parte tiende a ser excluido del contenido esencial del derecho a la presunción de inocencia”. FERNÁNDEZ, Prueba y Presunción de inocencia, cit. nota nº 32, pp. 157-158.
} 


\title{
BELTRÁN, Ramón. "Estándares de prueba y su aplicación sobre el elemento material de la prisión preventiva en Chile".
}

\begin{abstract}
“(...) es indispensable confiar a la rectitud y al sano criterio del magistrado gran parte de lo que debiera en rigor hallarse consignado en la ley, pues no hay precepto alguno general, por claro y perfecto que suponga, que pueda suplir a la apreciación juiciosa de los hechos, propia sólo del tribunal que los ve y los pesa". ${ }^{34}$
\end{abstract}

Y, por otro lado, se eliminaría la clásica distinción entre certeza legal condenatoria y certeza moral absolutoria establecida a partir del artículo 456 bis del antiguo Código de Procedimiento Penal de 1906, a fin de reducir los perniciosos efectos del sistema de prueba legal o tasada. ${ }^{35}$

Sin embargo, y no obstante el sano intento en la superación del estándar psicológico de íntima convicción, ${ }^{36}$ la inclusión de la duda razonable en Chile no ha estado ausente de polémicas. La primera de ellas se observa cuando se analiza la respectiva discusión parlamentaria y se denota la carencia de estudios e investigaciones que hayan demostrado sus diversas implicancias y repercusiones. En efecto, el proyecto de Código originalmente no contenía mención alguna respecto al estándar en comento, siendo recién considerada su inclusión en el mes de Agosto del año 2000, es decir, 4 meses antes de la entrada en vigencia del Código. ${ }^{37}$ Dentro de las razones que se esgrimieron en aquél entonces, se señaló:

“el estándar de convicción 'más allá de toda duda razonable' es propio del derecho anglosajón, y no del europeo continental, por lo que resulta una novedad también para el ordenamiento jurídico chileno. Sin embargo, es un concepto útil, toda vez que está suficientemente decantado y elimina las discusiones relativas al grado de convicción

\footnotetext{
${ }^{34}$ Mensaje del Código Penal Chileno.

${ }^{35}$ Dicha distinción era interpretada por nuestros tribunales en el sentido que, no obstante existir plena prueba de culpabilidad, si el sentenciador no alcanzaba la convicción de que el procesado realmente hubiese cometido el hecho punible y correspondido en él una participación culpable y penada por la ley, concernía se decrete la absolución del mismo. Cfr. MORALES, Eduardo, Explicaciones de Derecho procesal, III: Derecho procesal penal, Santiago: edición privada, 1987, pp. 262-263.

${ }^{36}$ Luego, no obstante ello, como bien señala Coloma Correa: "Aún cuando resultase difícil de sostener seriamente que en el antiguo sistema de enjuiciamiento criminal los jueces debían condenar (o condenaban) sólo cuando existía certeza de que ciertos hechos previstos en el tipo penal habían ocurrido, el desconocimiento de un estándar de prueba provocaba distorsiones al interior del modelo". COLOMA, Rodrigo, "Panorama General de la Prueba en el Juicio Oral Chileno", en: EL MISMO (Coord.), La Prueba en el Nuevo Proceso Penal Oral, Santiago: LexisNexis, 2004, p. 26.

${ }^{37}$ Dentro de las razones materiales de fondo acerca de la introducción de la duda razonable en Chile, se han tendido a explicitar motivos de orden práctico, ya que, en virtud de la experiencia en el funcionamiento del juicio oral y los programas de entrenamiento de destrezas de litigación, cierto académicos habrían notado la necesidad de su incorporación de manera paralela a la discusión parlamentaria. En el desarrollo de estas actividades, se expresa: "constatamos que la magnitud del cambio del sistema probatorio derivado de la introducción de la oralidad era bastante mayor de lo que imaginábamos originalmente, y una de las preocupaciones que surgió (...), fue la de constatar que se requería dar una señal muy potente en cuanto a la necesidad de utilizar al juicio oral como un mecanismo muy poderoso para el análisis de la prueba en contextos de información restringida". RIEGO, Cristián, "Nuevo estándar de Convicción", Informe de Investigación $\mathrm{N}^{\mathrm{o}} 17$, año 5 (2003), p. 4.
} 
que se requiere, dejando en evidencia que no se trata de una convicción absoluta, sino de aquella que excluya las dudas más importantes". 38

Sin embargo, ni lo relativo a su concepto ni lo relativo a su grado de confirmación era efectivo, pues establecer lo que implica la expresión "más allá de duda razonable" no es un tema fácil. En la tradición anglosajona y, particularmente, en la norteamericana, por ejemplo, la comprensión del estándar referido ha planteado -desde un plano terminológicotantos problemas, que se ha llegado a sostener que reasonable doubt es un concepto que se autodefine por ser una noción autoevidente. ${ }^{39}$ Por tal motivo, sólo el jurado podría llegar a definir qué se entiende por duda razonable ${ }^{40}$ y el grado de convicción contextual que se espera. A mayor abundamiento, históricamente la duda razonable nació en el contexto del common law no por motivos de que tendieran a dar objetividad al control probatorio, o si se quiere, a dar salvaguarda al imputado frente a los hechos que se imputaban. Por el contrario, cuando se pensó en la duda razonable se pensó en un mecanismo que garantizará al jurado en lo espiritual, vale decir, que tendiera a avalar la salvación cristiana de sus miembros a fin de evitar que cayeran en pecado mortal. Se concretizó así el mandato de "no juzgar para no ser juzgados" (Mt 7:1-5) ${ }^{41}$ y se configuró un procedimiento en donde no sólo estaba en juego el destino del acusado sino también el de los jurados. ${ }^{42}$

Lo anterior ha redundado precisamente en el carácter subjetivo que se ha atribuido a la duda razonable. Se ha sostenido que el sistema de jurados es a todas luces intuitivo y circunstancial, basado en el parecer propio e individual que cada miembro posee en su conciencia; ${ }^{43}$ y que, en lo conceptual, la mayoría de las veces se inspira en la comprensión sesgada que cada jurado tiene acerca de lo que se entiende por duda y sus verdaderas imbricaciones prácticas. Sin embargo, y a fin de superar la anteriores críticas, se ha

\footnotetext{
${ }^{38}$ HISTORIA DE LA LEY No 19.696 , p. 2005.

39 El fundamento de esta regla, se ha señalado, se encontraría en la convicción de que los esfuerzos para definir toda duda razonable en vez de aclarar el concepto producirían el efecto contrario, es decir, confundirían el mismo. Así, se ha manifestado que: "This rationale is challenged when, as in the present case, a jury specifically requests a definition of reasonable doubt. We understand that when a jury specifically requests a definition of reasonable doubt during deliberations, there is a risk that the jury may be confused over what standard of proof to apply in a criminal case (...) Nevertheless, we remain convinced that attempting to explain the words "beyond a reasonable doubt" is more dangerous than leaving a jury to wrestle with only the words themselves". "United States v. Walton", (Case n 97-4498/97-4537.). En un mismo sentido, vid. "Holland v Ohio", 348 U.S. 121 (1954).

${ }^{40}$ Vid. "United States v. Headspeth", 852 F.2d 753, 755 (1988).

${ }^{41} \mathrm{Y}$ también lo señalado en el libro de los Proverbios: "Justificar al malo y condenar al justo: ambas cosas abomina Yaveh" (Prov. 17:15).

${ }^{42}$ Como bien explica Whitman: "In the Christian past (...), there was more at stake, in a criminal trial, than the fate of the accused. The fate of those who sat in judgment was at stake at well. The famous injunction on Saint Matthew -judge not lest ye be judged!- had a concrete meaning: convicting an innocent defendant was regarded, in the older Christian tradition, as a potential mortal sin. The reasonable doubt rule was one of many rules and procedures that developed in response to this disquieting possibility. It was originally a theological doctrine, intended to reassure juror that they could convict the defendant without risking they own salvation, so long as their doubts about guilt were not reasonable. Beyond a reasonable doubt, was originally a rule for anxious Christians, living in an age haunted, as our world no longer is, by the fear of damnation". WHITMAN, James, The Origins of Reasonable Doubt: Theological Roots of the Criminal Trial, New Haven: Yale University Press, 2008, p. 3.

${ }^{43}$ Vid. LAUDAN, "Por qué un estándar", cit. nota n 13, pp. 100.
} 


\section{BELTRÁN, Ramón. "Estándares de prueba y su aplicación sobre el elemento material de la prisión preventiva en Chile".}

sostenido que el citado estándar no sería subjetivo sino objetivo, dado que en el sistema europeo continental no existe el jurado, además de que los jueces que dictan el respectivo veredicto poseen una formación profesional y no lega, lo que permitiría dotar de mayor razonabilidad y justificación al mismo. ${ }^{44}$

Luego, más allá del carácter subjetivo u objetivo que se pueda predicar del citado estándar, si con la introducción de la duda razonable se buscaba por el legislador introducir una pauta de alta certidumbre a fin de determinar cuándo resulta justificado por el juez aceptar o rechazar una determinada proposición fáctica en razón su razonamiento probatorio, ${ }^{45}$ no se observa cómo y de qué manera ${ }^{46}$ es posible establecer ese grado de convicción en circunstancias que legislativamente hablando no se entregaron herramientas para ello. ${ }^{47}$ Como resultado de lo anterior, se observa que en la praxis judicial chilena los tribunales sólo se limitan a dar por fundada dicha convicción - como han sostenido algunos autorescon la mera afirmación de haberla alcanzado. ${ }^{48}$ Por ello, dicho umbral por su alto grado de

\footnotetext{
${ }^{44}$ Para aquellos que sustentan en nuestro medio el carácter objetivo de este umbral de convicción, se señala que, de manera monocorde con el enunciado del artículo 340 del C.P.P., se debe interpretar el artículo 297 del mismo cuerpo adjetivo, el cual permitiría dotar de cierta razonabilidad objetiva el componente factico acreditado en juicio. Al respecto Vid, ACCATINO, Daniela, "El modelo legal de justificación de los enunciados probatorios en las sentencias penales y su control a través del recurso de nulidad", en: ACCATINO, Daniela (Coord.), Formación y valoración de la prueba en el proceso penal, Santiago: Legal Publishing, 2010, pp. 137 y ss.

${ }^{45}$ Cfr. ACCATINO, Daniela, "Certezas, dudas y propuestas en torno al estándar de la prueba penal”, Revista de Derecho de la Pontificia Universidad Católica de Valparaíso no 37 (2011), pp. 483-511.

${ }^{46} \mathrm{Sin}$ emitir un juicio de valor a su respecto, conviene precisar que un sector de la doctrina recientemente ha sostenido que, frente a la existencia de un voto disidente emanado del Tribunal del Juicio Oral, existiría un padrón base a considerar respecto de cuando se ha de estimar que hay "duda razonable". Así, si arrancamos de la base que la composición de dicho tribunal es de tres integrantes y, de acuerdo al estándar referido, se exige un umbral particularmente elevado para así corroborar la inocencia o culpabilidad del acusado, parece incongruente que se verifique igualmente una decisión de condena a pesar de existir un voto disidente que demuestre fundadamente que ha existido una duda razonable. En este último sentido, según algunos, existen argumentos suficientes para considerar que, en la existencia de un voto disidente motivado y justificado respecto de la quaestio facti, no cabe otra posibilidad que absolver al acusado por cuanto "si nuestro proceso penal tiene una pretensión de búsqueda de verdad -epistémica, no formal como equivocadamente se sostienecomo legitimación del castigo estatal, aquella debe ser impuesta cuando -al menos desde una perspectiva material-, existe unanimidad de los jueces en cuanto a la condena”. CARNEVALI, Raúl; CASTILLO, Ignacio, "El estándar de convicción de la duda razonable en el proceso penal chileno, en particular la relevancia del voto disidente", Ius et Praxis, año 17, $\mathrm{n}^{\mathrm{o}} 2$ (2011), p. 83. En un sentido similar, aunque no idéntico, apelando a que la estructura de la duda razonable es equivalente al de la "duda razonada", de modo que cada vez que exista un voto disidente el estándar de prueba no debiera considerarse satisfecho, a pesar de la decisión de la mayoría. Vid. ETCHEVERRY, Alfredo, "Consideraciones sobre el criterio de condena en el código procesal penal”, en RODRÍGUEZ, Luis (Coord.), Delito, pena y proceso. Libro homenaje a la memoria del profesor Tito Solari Peralta, Santiago: Editorial Jurídica de Chile, 2008, pp. 659-678.

${ }^{47}$ En dicho sentido, sostiene Jordi Ferrer Beltrán que "a falta de un criterio de razonabilidad de la duda, esta formulación del estándar de prueba penal no consigue superar los problemas señalados para la íntima convicción, que los hacen inservibles como estándares de prueba (...). Es decir, por su vaguedad extrema, no indican un umbral o nivel de suficiencia de la prueba que sea intersubjetivamente controlable". FERRER, Jordi, La valoración racional de la prueba, Barcelona: Marcial Pons, 2008, p. 146.

48 Como acertadamente explica Accatino, en la mayoría de las resoluciones judiciales dictadas por los Tribunales de Juicio Oral en Lo Penal es reiterativa la invocación -casi como una especie de mantra- de que sobre la base de los elementos de prueba rendidos en juicio y "valorados con libertad y sin contradecir los principios de la lógica, las máximas de la experiencia y los conocimientos científicamente afianzados, el
} 
Polít. crim. Vol. 7, No 14 (Diciembre 2012), Art. 6, pp. 454 - 479.

[http://www.politicacriminal.cl/Vol_07/n_14/Vol7N14A6.pdf]

permeabilidad -incluso en el propio sistema del common law- poco a poco sido desplazado por otros estándares en principio más fiables. ${ }^{49}$

\section{Requisitos de la prisión preventiva en Chile y su determinación fáctica.}

De todas las medidas coercitivas de carácter cautelar que se puedan verificar en el proceso penal, ninguna preocupa tanto y ha sido objeto de tanta atención legal y jurisprudencial como la prisión preventiva. Ello, en todo caso, parece lógico, ya que ningún instrumento procesal afecta con tal magnitud los derechos fundamentales del imputado, que, no olvidemos, mientras pende el juicio se considera para todos los efectos legales como inocente.

Sabido es que la regulación legal de la prisión preventiva en nuestro Derecho no es algo reciente. En efecto, desde su instauración por la Ley $\mathrm{N}^{\mathrm{o}} 1.853$, de 19 de enero de 1906, hasta su última modificación por la Ley $\mathrm{N}^{\mathrm{o}} 20.253$, de 14 de marzo de 2008, dicho instituto cautelar ha experimentado por vía legal más de 30 modificaciones a lo largo de su historia. Pueden ser muchos los argumentos utilizados para avalar tal postura, sin embargo, nada más que la valoración sostenida de inseguridad y la efervescencia política tienden a explicar su constante mutación.

La doctrina, a este respecto, desde antiguo ha tratado de entregar argumentos de variada índole a fin de justificar la procedencia de la prisión preventiva. ${ }^{50}$

En nuestro medio, el artículo 140 del Código Procesal Penal dispone que:

"una vez formalizada la investigación, el tribunal, a petición del Ministerio Público o del querellante, podrá decretar la prisión preventiva del imputado siempre que el solicitante acreditare que se cumplen los siguientes requisitos: a) Que existen antecedentes que justificaren la existencia del delito que se investigare; b) Que existen antecedentes que permitieren presumir fundadamente que el imputado ha tenido participación en el delito como autor, cómplice o encubridor, y c) Que existen antecedentes calificados que permitieren al tribunal considerar que la prisión

\footnotetext{
tribunal ha adquirido la convicción, más allá de toda duda razonable, que se encuentran acreditados los siguientes hechos". Vid, ACCATINO, "Certezas, dudas y propuestas", cit. nota no 45, p. 496.

${ }^{49}$ En Inglaterra, por ejemplo, la duda razonable ha sido sustituida por el estándar de "la firme convicción". Al respecto señala Laudan: "Es sintomático de la desesperación que rige la situación actual del sistema del common law en Inglaterra el reciente abandono del reclamo para que los jurados utilicen el estándar razonable de la duda y su reemplazo de manera oficial por el estándar de la firme convicción. Esto no es tanto un cambio en la práctica como un reconocimiento explícito de lo que la práctica existente ha llegado a ser". LAUDAN, "Por qué un estándar", cit. nota no 13, p. 100.

50 Siguiendo a Giovanni Leone, puede señalarse que la prisión preventiva ha encontrado fuentes de legitimación en diversas razones: a) En asegurar la persona del imputado para el proceso (Manszini); b) En Asegurar la disponibilidad del imputado como fuente de prueba (Hippel, Stock, Vassalli y De Marsico); c) En impedir que el imputado pueda influir sobre la genuina recepción de las pruebas (Carnelutti); En garantizar el resultado del proceso (De Luca); e) En la defensa social proporcionada a la gravedad del delito y a la peligrosidad del imputado (Novelli) y; f) En la prevención general, en el sentido de impedir que la victima (o las personas allegadas a la victima) de un grave delito pase a actos de venganza (Vasalli). Vid. LEONE, Giovanni, Tratado de derecho procesal Penal, Buenos Aires: El Foro, 1963, pp. 259 y ss.
} 
BELTRÁN, Ramón. "Estándares de prueba y su aplicación sobre el elemento material de la prisión preventiva en Chile".

preventiva es indispensable para el éxito de diligencias precisas y determinadas de la investigación, o que la libertad del imputado es peligrosa para la seguridad de la sociedad o del ofendido, o que existe peligro de que el imputado se dé a la fuga, conforme a las disposiciones de los incisos siguientes."

A propósito de dicho enunciado es común aglutinar genéricamente dichas condiciones en la concurrencia de dos supuestos: uno material y otro cautelar. Respecto al criterio material, de acuerdo con el artículo 140 letras a) y b), para que el juez pueda decretar la prisión preventiva, debe considerar que los antecedentes presentados por el fiscal demuestren la existencia del hecho punible y den cuenta de presunciones fundadas de participación del imputado. Con dicha exigencia, lo que se intenta -mirado desde el punto de vista argumental- es sustentar la existencia de una imputación suficientemente seria en base a antecedentes sólidos que permitan proyectar la realización del juicio y una eventual condena. Respecto al criterio cautelar, de acuerdo a la letra c) del citado artículo, la prisión preventiva se nos presenta como una medida cautelar personal $\mathrm{y}$, de este modo, como un medio o instrumento idóneo afecto a un fin determinado.

A este respecto, sin eludir las fundadas críticas respecto del último criterio esbozado, ${ }^{51}$ nos abocaremos al estudio del elemento material de la prisión preventiva, a fin de vincularlo con la necesidad o no de establecer en su apreciación un estándar que delimite la razonabilidad fáctica de su estructuración, es decir, de determinar qué nivel de corroboración se considera suficiente para ordenar la adopción de la prisión preventiva durante la fase de investigación penal.

En un primer orden de ideas, diremos que el establecimiento del elemento material en la prisión preventiva responde a la exigencia del fumus delicti comissi, equiparable con el fumus boni iuris en Derecho civil, y que, respecto a la prisión preventiva, comprende la obligación del solicitante de "acreditar" que existen antecedentes que justificaren la existencia del delito que se investigare y que existen antecedentes que permitieren presumir fundadamente que el imputado ha tenido participación en el delito como autor, cómplice o encubridor. Como es posible advertir, el Código Procesal Penal optó por mantener en esta materia los mismos requisitos que el sistema inquisitivo imponía para la dictación del auto

51 Dentro de las críticas que es posible formular elemento cautelar de la prisión preventiva, en primer término, es posible señalar que ésta no es diferenciable de la pena privativa de libertad que finalmente está asegurando. La prisión preventiva importa una privación de libertad del inocente de la misma forma fáctica que la pena condenatoria que eventualmente se le pudiera imponer, funcionando, a este respecto, como una verdadera condena anticipada del preso preventivo. En segundo lugar, en nuestro medio el hecho que el legislador establezca a la prisión preventiva en la hipótesis de que la libertad del imputado constituya un riesgo para la seguridad de la sociedad, supone un baremo tan amplio que aleja a dicho instituto de todo objetivo cautelar vinculado al proceso. Así, que un sujeto no cometa un delito en el futuro no es un objetivo en el que, de hecho, este es tenido como presunto inocente, sino más bien un objetivo de prevención especial propio de la pena o de una medida de seguridad. A este respecto, Vid. HASSEMER, Winfried, "Los presupuestos de la prisión preventiva", en: DEL MISMO, Crítica al Derecho Penal de Hoy. Normas, Interpretación, Procedimiento. Limites a la Prisión Preventiva. Trad. Patricia S. Ziffer. Buenos Aires: AdHoc, 2003, pp. 103 y ss. FERRAJOLI, Luigi. Derecho y razón. Teoría del Garantismo Penal. Trad. Perfecto Andrés et al, Madrid: Trotta, 1995, pp. 555 y ss.; DUCE, Mauricio; RIEGO, Cristian, La Prisión Preventiva en Chile: Análisis de los Cambios Legales y su Impacto, Santiago: Ediciones UDP, 2011, pp. 34 y ss. 


\section{Polít. crim. Vol. 7, No 14 (Diciembre 2012), Art. 6, pp. 454 - 479. [http://www.politicacriminal.cl/Vol_07/n_14/Vol7N14A6.pdf]}

de procesamiento, ${ }^{52}$ conforme a lo previsto por el art. 274 Código de procedimiento penal de $1906 .^{53}$

Así las cosas, una primera interpretación exegética y literal respecto de lo esbozado nos puede llevar a concluir que no existe regulación alguna respecto de la existencia a algún estándar de prueba en materia de prisión preventiva. De esta forma, la decisión que se adopte respecto al misma seria sólo "intime conviction" incontrolable por la vía de la corrección fáctica, es decir, no sería posible determinar si se ha superado o no el umbral mínimo de corroboración de la hipótesis enjuiciada. Sin embargo, es claro que tal interpretación no es satisfactoria, pues, la justificación de antecedentes -más bien el peso de éstos- implica un elevado grado de convencimiento sobre la existencia de un delito y la participación en él del imputado, que no puede estar entregado a la mera discrecionalidad del sentenciador, sino, por el contrario, por los derechos involucrados, exige un mayor rigor estatal en la argumentación penal a costa de la libertad del sospechoso. ${ }^{54}$

Luego, es evidente que sobre dicha estructuración fáctica no es posible precisar el umbral de la duda razonable. Ello, porque más allá de contar sólo con antecedentes de naturaleza indiciaria, ${ }^{55}$ aunque fundados, en estricto rigor no es posible predicar de ellos una certeza en ausencia de duda. Adicionalmente, de otro lado, el razonamiento inductivo de los antecedentes en la prisión preventiva, no importa per se una apreciación final de la actividad probatoria, como es exigible en la duda razonable, sino más bien una apreciación provisional y temporal de la misma, que puede desvanecerse en cualquier etapa del procedimiento. Así,
"cuando analizamos los fundamentos de esta decisión provisional tenemos que tener presente que ni el juez en el caso particular, ni el sistema en su conjunto, quieren abrir una discusión en profundidad sobre la prueba; hacerlo significaría anticipar el juicio oral y dar a la decisión jurisdiccional mayor consistencia y, con ello, potencialmente mayor permanencia". 56

A mayor abundamiento, usar la duda razonable para elevar la exigencia de acreditación, tampoco significaría necesariamente una mayor tutela y salvaguardia de los derechos del

\footnotetext{
52 En el antiguo Código de Procedimiento Penal, que consagraba un sistema de prueba tasada, estas expresiones -que esté acreditado el hecho punible y que existan presunciones fundadas de participación- se entendían como un estándar claramente inferior al de plena prueba requerido como regla general para la condena. Mayores antecedentes sobre esta lógica, Vid. QUEZADA, José, Tratado de derecho procesal penal, Santiago: Ediar-Conosur, 1994, pp. 253 y ss.

${ }^{53}$ Dicha norma preceptuaba: "Después que el juez haya interrogado al inculpado, lo someterá a proceso, si de los antecedentes resultare: $1^{\circ}$ Que está justificada la existencia del delito que se investiga, y $2^{\circ}$ Que aparecen presunciones fundadas para estimar que el inculpado ha tenido participación en el delito como autor, cómplice o encubridor. El juez procesara al inculpado por cada uno de los hechos punibles que se le imputen, cuando concurran las circunstancias señaladas".

${ }^{54}$ Vid. CASTRO, Javier, Introducción al Derecho procesal penal chileno, Santiago: LexisNexis, 2008, p. 282.

${ }^{55}$ Sobre la valoración fáctica de los indicios y sus repercusiones, Vid. CALVO, José "Hechos difíciles y razonamiento probatorio (Sobre la prueba de los hechos disipados)", Anuario de filosofia del Derecho $\mathrm{n}^{\circ} 18$ (2001), pp. 13-34.

${ }^{56}$ DUCE/RIEGO, La prisión preventiva en Chile, cit. nota ${ }^{\circ} 51$, p. 38.
} 
BELTRÁN, Ramón. "Estándares de prueba y su aplicación sobre el elemento material de la prisión preventiva en Chile".

imputado, sino, por el contrario, en la mayoría de los casos supondría fortalecer la decisión de privación de libertad inicial y proyectarla a todas las etapas del procedimiento en especial en la sentencia.

La doctrina nacional sin cuestionar ni refrendar lo anterior, no ha entregado, en todo caso, mayores aportes respecto de la problemática asociada a la determinación del estándar fáctico en la prisión preventiva. Horvitz y López, ${ }^{57}$ por ejemplo, sostienen ambiguamente acudiendo a las nociones de duda, probabilidad y certeza planteadas por Maier ${ }^{58}$ que la norma chilena permitiría sostener que la letra b) del Artículo 140 del Código Procesal Penal exigiría una probabilidad y la letra a) una certeza. En la misma senda, Blanco y otros sostienen que:

"al solicitar la prisión preventiva, el fiscal debe acreditar ante el juez "la plausibilidad del caso". Se trata de una exigencia menor en términos probatorios que las que rigen para dictar sentencia en el juicio oral; y el tribunal debe limitarse a verificar si se cumplen o no los supuestos legales y si están demostrados los antecedentes concretos". 59

Por otro lado, Duce y Riego postulan que, por ser una apreciación temprana, el juez frente a una solicitud de prisión preventiva debe verificar la seriedad de los cargos, esto es, que la información con que cuenta el fiscal

“tenga los elementos necesarios que permitan fundamentar los cargos de un modo suficientemente convincente, en términos de prever que habrá de llevarse adelante un juicio en el que la prueba será examinada pormenorizadamente y que luego será valorada en la sentencia". 60

Ahora bien, tampoco es muy decidor lo que en el Derecho comparado se ha establecido al respecto. Alemania, por ejemplo, en vez de usar "el carácter de seriedad" exigido antiguamente por nuestro legislador, exige como elemento material que exista "una sospecha vehemente" de que el imputado ha cometido el hecho punible. ${ }^{61}$ El sistema norteamericano, a su vez, habla de "causa probable" de la ocurrencia del hecho delictivo y

\footnotetext{
57 Vid. HORVITZ, Ma Inés; LÓPEZ, Julián, Derecho Procesal Penal Chileno, t. I, Santiago: Editorial Jurídica de Chile, 2003, pp. 401 y ss.

58 Al respecto dice Maier: "Quien aprecia los elementos de prueba puede, sin embargo, adoptar decisiones diferentes respecto de la verdad: puede convencerse de que la ha alcanzado, tiene la certeza de que su reconstrucción es correcta; se inclina a admitir que ha alcanzado la verdad, pero en un grado menor al anterior, pues los elementos que lo afirman en esa posición superan a otros que la rechazan, hábiles sin embargo para evitar su convicción total de haber elaborado un juicio correcto, sin errores, afirma la probabilidad de que su reconstrucción es acertada; por último, comprende que no conoce la verdad, pues los elementos que afirman algo se balancean con los que lo niegan, la duda es absoluta". MAIER, Julio, Derecho procesal penal, Buenos Aires: Editores del Puerto, 1989, p. 258.

${ }_{59}$ BLANCO, Rafael et al, Litigación estratégica en el nuevo proceso penal, Santiago: LexisNexis, 2005, pp. 68-69.

${ }^{60}$ DUCE, Mauricio; RIEGO, Cristián, Proceso Penal, Santiago: Editorial Jurídica de Chile, 2007, p. 252.

${ }^{61}$ Vid. ROXIN, Claus, Derecho procesal penal, Buenos Aires: Editores del Puerto, 2000, pp. 259 y ss.
} 


\section{Polít. crim. Vol. 7, No 14 (Diciembre 2012), Art. 6, pp. 454 - 479. [http://www.politicacriminal.cl/Vol_07/n_14/Vol7N14A6.pdf]}

de participación del imputado en el mismo. ${ }^{62}$ El sistema Colombiano, por último, acercándose más a la noción de seriedad de cargos, refiere al hecho de "inferir razonablemente" que el imputado puede ser autor o participe de la conducta delictiva que se investiga. $^{63}$

Sin embargo, pensamos, dichas aseveraciones -desde un plano epistemológico- no han dado respuesta respecto del grado de refutación probabilista que sirve de base al tiempo de considerar un estándar, es decir, no consideran el quantum de error permitido en la aceptabilidad de las aserciones fácticas que sirven de apoyo en la decretación de la prisión preventiva.

Por la razones arriba anotadas, no resulta plausible aplicar al caso que nos ocupa la duda razonable; luego, tampoco se podría aplicar el sistema de prueba prevalente pues su umbral establecido en la premisa "más razonable que no" es muy bajo respecto de las garantías y tópicos que supone la privación de libertad del inocente. ${ }^{64}$

De esta forma, evidenciando que el proceso penal exige de diversos estándares de prueba en relación a los distintos tipos de decisiones que supone, se hace necesario buscar un estándar que atribuya un grado de confirmación fáctica intermedio entre los estándares propugnados, y que, intentado superar su criticado carácter subjetivo, nos permita saltar los inconvenientes de la "encubierta" intima convicción vigente en el actual sistema. ${ }^{65}$

Con todo, una primera aproximación de lo anterior, nos podría llevar a pensar que el referido umbral corresponde al estándar de prueba "clear and convincing evidence" también llamado "clear, convincing, and satisfactory".

Dicho baremo, cuyo origen al parecer se encontraría en las Cortes inglesas de equidad ${ }^{66}$, se fundamentaría en base a ciertas materias que, por su naturaleza e interés, ${ }^{67}$ harían

\footnotetext{
${ }^{62}$ Vid. THAMAN, Stephen. "Detención y prisión provisional en los Estados Unidos", Cuadernos de Derecho Judicial $\mathrm{n}^{\circ} 18$ (1996), Detención y prisión preventiva, pp. 193-226.

${ }^{63}$ A su respecto, el artículo 308 del Código de Procedimiento Penal Colombiano de 2004 señala: "El juez de control de garantías, a petición del Fiscal General de la Nación o de su delegado, decretará la medida de aseguramiento cuando de los elementos materiales probatorios y evidencia física recogidos y asegurados o de la información obtenidos legalmente, se pueda inferir razonablemente que el imputado puede ser autor o partícipe de la conducta delictiva que se investiga (...)".

64 Además conviene recordar que este umbral puede considerarse "mínimo", ya que un estándar menos exigente implicaría que se debiera tener por probada una hipótesis menos corroborada, o, dicho de otro modo, menos probablemente verdadera que otras hipótesis sostenidas en el proceso, ya que como señala Taruffo: "sería irracional dejar que el juzgador eligiera la versión de los hechos que esté menos apoyada por los medios de prueba". TARUFFO, Michele, La prueba, Trad. Laura Manríquez y Jordi Ferrer, Barcelona: Marcial Pons, 2008, p. 138.

${ }^{65}$ Para una interesante propuesta al respecto, Vid. COLOMA, Rodrigo, "Estándares de Prueba y Juicios por Violaciones a los Derechos Humanos", Revista de Derecho (Valdivia), vol. XXII, n² 2, (2009), pp. 205-229.

${ }^{66} \mathrm{Al}$ respecto, la misma jurisprudencia norteamericana ha sostenido: "That rule ... arose at a time when such suits were cognizable only in courts of chancery where matters of fact, as well as of law, were tried by the chancellor. Verdicts of juries in those courts were advisory only. In our blended system the field in which that rule operates is very narrow. In practical effect is but an admonition to the judge to exercise great caution in weighing the evidence". "Sanders v. Harder" (1950) 148 Tex. 593, 598-99, 227.
} 
BELTRÁN, Ramón. "Estándares de prueba y su aplicación sobre el elemento material de la prisión preventiva en Chile".

aconsejable un control ecléctico en la distribución del error, esto es, exigiendo un umbral de probabilidad superior al constatado en la prueba prevalente e inferior al verificado en la duda razonable. Se trataría por lo mismo de un estándar intermedio, ${ }^{68}$ que, como explica McBaine, importa que:

“el juez, si el juez determina los hechos, o el jurado, si el jurado determina los hechos, debe creer que es altamente probable que lo hechos sean verdaderos o existen; aunque no es necesario creer al punto de casi certeza, o más allá de una duda razonable que son verdaderos o existen, o que ellos ciertamente son verdaderos o existen; aunque no es suficiente [tampoco] para creer que es simplemente más probable que ellos sean verdaderos o existan o que sean falsos o no existan". 69

En términos de la jurisprudencia norteamericana, la verosimilitud exigida por este estándar -en la probabilidad de ocurrencia fáctica- requeriría que "la evidencia sea tan clara como para no dejar dudas sustanciales", 70 es decir, que sea "lo suficientemente fuerte para dirigir el asentimiento sin titubeos de toda mente razonable". ${ }^{71}$ Luego, su carácter claro y convincente, serviría precisamente para predicar su cariz eclécticamente intermedio: "la evidencia será clara en el sentido de que es cierta, simple a la comprensión, inequívoca; y convincente en el sentido de que es tan razonable y persuasiva como para hacer que cualquiera la crea". ${ }^{72}$

Ahora bien, como es posible advertir, no son menores las críticas que se pueden librar en contra de dicho baremo. En primer lugar, y al igual que en el caso de la duda razonable, no se han entregado mayores parámetros acerca de cuál sería quantum exigido para tener por confirmada la hipótesis que se entiende acreditada o refutada. ${ }^{73}$ Luego, en esta misma línea, tampoco se ha clarificado el punto de comparación sobre el cual se cimentaría el análisis de

\footnotetext{
${ }^{67}$ Se trata de casos referentes, entre otros, a indemnizaciones de perjuicios, casos de deportaciones a inmigrantes, violencia en el contexto intrafamiliar, etc. Para ver en detalle los casos en los cuales la jurisprudencia estadounidense ha hecho aplicación de este estándar, vid. PATTENDEN, Rosemary, "The risk of non-persuasion in civil trials: the case against a floating standard of proof ", Civil Justice Quarterly $n^{\circ} 7$ (1989), pp. 220-233.

${ }^{68}$ Cfr. CLERMONT, Kevin; SHERWIN, Emily, "Comparative View of Standards of Proof", The American Journal of Comparative Law, Vol. 50, n 2 (2002), p. 251.

69 "The judge, if the judge finds the facts, or the jury, if the jury finds the facts, must believe that it is highly probable that the facts are true or exist; while it is not necessary to believe to the point of almost certainty, or beyond a reasonable doubt that they are true or exist, or that they certainly are true or exist; yet it is not sufficient to believe that it is merely more probable that they are true or exist than it is that they are false or do not exist" (traducción propia). McBAINE, J.P., "Burdens of Proof: Degrees of Belief", California Law Review, Vol. 32 (1944), pp. 262-263.

70 "In re Angelia P" (1981) 28 Cal.3d 908.

71 “Sheehan v. Sullivan” (1899) 126 Cal 189, 193 [58 p 543]; En un mismo sentido, "In re Terry D” (1978) 83 Cal.App.3d, 890 [148 Cal. Rptr. 221].

72 "State v. Renforth" (1987), 155 Ariz. Ct. App. 385, 746 P.2d 1315.

${ }^{73}$ Se ha sostenido que, en términos porcentuales, correspondería a un 75\%, 60\% e incluso un $80 \%$. En este sentido, como explica McBaine: "Nosotros no podemos tan fácilmente formular una regla para un estado mental como si pudiéramos idear un método para encontrar si un recipiente que contiene agua se encuentra en un 55 o 75\% lleno" (la traducción es mía). McBAINE, "Burdens of Proof:”, cit. nota n 69, p. 254.
} 
Polít. crim. Vol. 7, No 14 (Diciembre 2012), Art. 6, pp. 454 - 479.

[http://www.politicacriminal.cl/Vol_07/n_14/Vol7N14A6.pdf]

"alta probabilidad de ocurrencia de los hechos"74 exigido. En su faz técnica, adicionalmente, tampoco se ha logrado clarificar específicamente cómo y de qué modo se distribuiría el riesgo de error tolerado en su aplicación. Por lo mismo, los propios tribunales norteamericanos han llegado a afirmar que dicho umbral, por su relativa similitud con la duda razonable, en vez de facilitar la tarea del jurado la entorpece. ${ }^{75}$

Así las cosas, se hace necesario superar tal indeterminación y buscar un mecanismo más concreto de determinación factual aplicable a la prisión preventiva. Para tratar de responder a lo anterior, prima facie conviene recalcar que -en nuestro entender- esta materia dependerá mucho de los criterios político-criminales que estén detrás de la idea de culpabilidad e inocencia sostenida por un Estado. Así, la mayor o menor potestad en la persecución criminal; la mayor o menor amplificación en los derechos de los intervinientes; o bien, la mayor o menor potestad en las facultades jurisdiccionales, servirán de reflejo respecto del grado de sensibilidad estatal que se predique en la distribución del riesgo tolerado. Como explica Gascón:

"la construcción de un estándar no depende sólo ni fundamentalmente de cuestiones de racionalidad, sino también y sobre todo de cuestiones de policy. Ello es así porque un estándar de convicción establece una determinada distribución del error, y una distribución del error supone una determinada elección (político-valorativa) sobre la intensidad con que deben ser garantizados los derechos e intereses afectados por cada uno de los errores posibles". 76

Ahora bien, las razones respecto de por qué se necesitaría un umbral de estas características, se basan a lo menos en dos consideraciones: La primera de ellas establecida por la misma presunción de inocencia ya explicada, que si bien en este caso no es derrotada, constituiría un criterio epistemológico con claras repercusiones prácticas. Es decir, se tratará de un criterio teórico que buscará responder a un interés cognoscitivo en aras de satisfacer un fin práctico, esto es, se garantizará el mayor grado de aproximación a la verdad sustentada por la hipótesis acusatoria y, de este modo, se garantizará un exclusivo fin: que no se prive innecesariamente de libertad al inocente. La segunda razón obedece a la pretensión de compensar una asimetría evidente. El ministerio público, por un lado, cuenta como ente persecutor encargado de la investigación, con todos los mecanismos técnicos y profesionales para desarrollar dicha actividad; la defensa y el imputado, por el contrario, carecen en general de tal potestad.

En este estadio no es difícil explicar entonces que la prisión preventiva requiere -como se dijo- un estándar sui generis, a fin de corregir la asignación del riesgo de error que

\footnotetext{
${ }^{74}$ Pardo y Allen lo traducen en la exigencia que la hipótesis que se tenga por probada sea "suficientemente más plausible". Cfr. PARDO, M. S. y ALLEN, R. J., "Juridical Proof and the Best Explanation", Law and Philosophy $\mathrm{n}^{\circ} 27$ (2008), pp. 223-268.

${ }^{75}$ Por ejemplo, la Corte Suprema de Arizona anuló un juicio en el cual el jurado fue instruido acerca de la prueba clara y convincente de la forma conceptualizada en el caso "Sheehan". Es más, dicho tribunal señaló expresamente que la especificación de dicho estándar era de duda razonable y no de prueba clara y convincente. Cfr. "State v.King" (1988) 158 Ariz. 419, 763 R2d 239.

${ }^{76}$ GASCÓN, Marina, "Sobre la posibilidad de formular estándares de prueba objetivos", Revista Doxa $\mathrm{n}^{\mathrm{o}} 28$ (2005), p. 20.
} 
BELTRÁN, Ramón. "Estándares de prueba y su aplicación sobre el elemento material de la prisión preventiva en Chile".

resultaría del mismo. El único modo de efectuar esa corrección, a nuestro entender, consistiría en no tener por probada sin más la hipótesis que tenga un grado de confirmación mayor, sino, adicionalmente, exigir que además de tener un grado de confirmación mayor, se alcance un quantum de confirmación determinado.

Ese plus o quantum adicional exigido respecto de la hipótesis de confirmación mayor, supone que, en la prisión preventiva, la hipótesis de existencia y participación exigida en su faz material, sólo será aceptada si junto a la contrastación y explicación de los datos disponibles se es posible, como aditamento, aportar datos que también hayan sido corroborados y confirmados, como sería el caso, por ejemplo, de probanzas incriminatorias con un contraste variado. ${ }^{77}$ Ello se entiende, naturalmente, sólo en el evento que se haya cumplido con la condición de refutación de la hipótesis de existencia del hecho punible y participación culpable, pues, como señala Ferrer Beltrán: "deben haberse refutado todas las demás hipótesis plausibles, explicativas de los mismos datos, que sean compatibles con la inocencia". ${ }^{78}$

Lo anterior, en todo caso, puede para algunos no resultar del todo novedoso. Ello, porque puede implicar casi una obviedad sostener que si ya se cuenta con muchos datos confirmatorios, la adición de un dato favorable aumentará el grado de confirmación. Sin embargo, si se analiza con detenimiento dicha afirmación, no resulta tan evidente. Así, cuando las diversas hipótesis confirmatorias están abonadas por un mismo dato confirmatorio, con idéntica contrastación, naturalmente se aumenta el grado de confirmación, pero levemente. Si, por el contrario, "los casos anteriores han sido todos ellos obtenidos mediante contrastaciones del mismo tipo, y el nuevo dato, en cambio, es el resultado de un tipo diferente de contrastación, la confirmación de la hipótesis se verá significativamente acrecentada". ${ }^{79}$

Lo primordial es, por lo tanto, asumir que ese plus o quantum adicional exigido para el modelo propuesto, sugiere entender que la confirmación de una hipótesis incriminatoria no depende sólo de la cantidad de antecedentes o datos favorables de que disponga el Ministerio Público, sino también de su variedad y calidad: así, cuanto mayor sea la variedad y calidad mayor será el apoyo de contraste resultante. Luego, no basta con lo anterior. En

\footnotetext{
${ }^{77}$ Entonces si, por ejemplo, el Ministerio Público afirma que "X mató a $Y$ con un revolver que tiene sus huellas digitales", existen tres medios eventuales para enervar tal afirmación. El primero de ellos fundado en la negación del contenido de la proposición diciendo " $X$ no mató a $Y^{\prime \prime}$; el segundo, ofreciendo pruebas de respaldo respecto de una afirmación incompatible con la sostenida, aseverando, por ejemplo "que las huellas encontradas en el revólver no pertenecen a $X^{\prime \prime}$; el tercero, ofreciendo una explicación diversa, por ejemplo, diciendo "que al momento de la muerte de $Y, X$ se encontraba fuera de la ciudad". Una vez que la defensa haya efectuado cualquiera de estas afirmaciones, corresponderá al Ministerio Publico aportar ese plus adicional al cual se hizo mención, realizando una corroboración de la hipótesis inicialmente sustentada, pero de contraste diverso. En el caso propuesto, aportando como prueba, por ejemplo, la respectiva pericia dactilar. Cfr. ANDERSON, Terence, "Visualization tools and argument schemes: a question of standpoint", Law, Probability and Risk $\mathrm{N}^{\circ} 6$ (2007), pp. 97-107.

${ }^{78}$ FERRER, Jordi, "Los estándares de prueba en el proceso penal español", Cuadernos electrónicos de filosofía del derecho $\mathrm{n}^{\circ} 15$ (2007), p. 6.

${ }^{79}$ HEMPEL, Carl, Filosofía de la Ciencia Natural, Trad. Alfredo Deaño. Madrid: Grupo Anaya Comercial, 2003, p. 58.
} 
Polít. crim. Vol. 7, No 14 (Diciembre 2012), Art. 6, pp. 454 - 479.

[http://www.politicacriminal.cl/Vol_07/n_14/Vol7N14A6.pdf]

nuestro entender, el esquema propuesto, a fin de predicar un telos respetuoso de los derechos fundamentales y, en particular, de los derechos del imputado, ha de establecer "una regla de cierre" a base de distribuir -como ya se adelantó- el onus probandi respecto de aquel interviniente que dispone de los medios y facilidades más amplias en la persecución punitiva, es decir, el Ministerio Público.

De esta forma, arrancando de refutación fáctica de la presunción de inocencia por parte del ente persecutor, pasado por la confirmación mayor de hipótesis de existencia y participación punibles, hasta llegar al aditamento de quantum de confirmación adicional exigida, pensamos, podría configurarse un estándar superior a la prevalencia e inferior a la duda razonable en materia de prisión preventiva.

Con todo, en su faz técnica, el esquema trazado supondrá que la información aportada por el fiscal -aunque indiciaria- deberá ser lo suficientemente contundente al tiempo de aportar datos confirmatorios de contrastación diversa respecto de la existencia y participación delictiva. Luego, no se trata de certeza, sino sólo de evidencia de suficiente intensidad que aporte una confirmación superior a la imputación formulada $\mathrm{y}$, respecto de la cual, el radio de acción de la defensa sea reducido a un límite tan estrecho, como para que convencionalmente la solicitud sea aceptada como verdadera sin mayores inconvenientes. Como se observa, se trata de una verdad sometida a revisión en merced de la pretensión técnica de contrariedad y refutación consistente en aportar buenas razones que hagan altamente plausible el caso propuesto.

De este modo, superando las diatribas y paradigmas propios de lo punitivo, pensamos que la prisión preventiva en su componente fáctico perfectamente puede ser confrontada en base al sistema recién descrito. En este sentido, se balancearían las garantías y derechos fundamentales en juego, al tiempo de configurarse un estándar en que sólo lograrían aceptabilidad las evidencias que lleguen a producir en el sentenciador un juicio probabilístico de convicción permanente, en el sentido de que las condiciones fácticas serían más que simplemente probables.

\section{Conclusiones.}

Dentro de los objetivos tenidos en vista al tiempo de elaborar el presente artículo, se pretendía esclarecer una serie de tópicos que rodean a la prueba de los hechos en materia de prisión preventiva.

Para lograr dicho cometido, se logró exponer, aunque sucintamente, la finalidad probatoria del proceso y el marco general de la verdad en su sentido tarskiano o relativo. Así, luego de describir la importancia de los estándares de convicción en la construcción de la quaestio facti, se dejo claro el rol de los sistemas de corroboración de hipótesis en dicho cometido. Luego, a diferencia de lo sustentado por la doctrina mayoritaria, se optó por enfatizar el rol de los estándares de convicción en consideración a la distribución del riesgo de error, desplazando, de este modo, la clásica compresión de los mismos como mera probabilidad fáctica de justificación. 
BELTRÁN, Ramón. “Estándares de prueba y su aplicación sobre el elemento material de la prisión preventiva en Chile".

Clarificado aquello, se pudo describir la prisión preventiva en atención a los elementos que la integran y, en particular, su elemento material. De este modo, es posible a razón de lo expresado extraer las siguientes conclusiones:

$1^{\circ}$ En nuestro país no existe normativamente hablando un baremo distinto a la duda razonable a fin de acreditar el componente fáctico que rodea el elemento material de la prisión preventiva.

$2^{o}$ Tampoco se evidencia un esfuerzo de la doctrina nacional en tratar de superar a la intima convicción en la apreciación del referido elemento.

$3^{\circ}$ Sin embargo, considerando que en el caso particular no es posible aplicar ni la prueba prevalente - por su carácter mínimo- ni la duda razonable - por su carácter máximo- se hace necesario trazar pautas de razonabilidad sobre las cuales erigir un estándar intermedio que supere las deficiencias hasta hoy constatadas.

$4^{\mathrm{o}}$ De este modo, se propone para la determinación de los hechos en la prisión preventiva en lo referente a la refrendación de su elemento material- un esquema tentativo de estandarización que superaría los problemas constatados. Así, por un lado, se propone que la refutación fáctica, recayendo en la parte persecutora, posibilite la salvaguarda de derechos tan importantes como la presunción de inocencia; y, por otro, que la confirmación mayor de existencia y participación, a fin de superar la simple prevalencia, suponga un plus adicional de corroboración tanto respecto de los antecedentes actuales como de los predecibles. 
Polít. crim. Vol. 7, No 14 (Diciembre 2012), Art. 6, pp. 454 - 479.

[http://www.politicacriminal.cl/Vol_07/n_14/Vol7N14A6.pdf]

\section{BIBLIOGRAFÍA}

ACCATINO, Daniela, "El modelo legal de justificación de los enunciados probatorios en las sentencias penales y su control a través del recurso de nulidad", en: ACCATINO, Daniela (Coord.), Formación y valoración de la prueba en el proceso penal, Santiago: Legal Publishing, 2010, pp. 137 y ss.

, "Certezas, dudas y propuestas en torno al estándar de la prueba penal”, Revista de Derecho de la Pontificia Universidad Católica de Valparaíso no 37 (2011), pp. 483-511.

,"Forma y Sustancia en el Razonamiento Probatorio. El Alcance del Control sobre la Valoración de la Prueba a través del Recurso de Nulidad Penal", Revista de Derecho de la Pontificia Universidad Católica de Valparaíso n ${ }^{0} 32$ (2009), pp. 347-362.

AGUILERA, Edgar, "Crítica a la "convicción íntima" como estándar de prueba en materia penal", Reforma Judicial, Revista Mexicana de Justicia no 12 (2008), pp. 5 y ss.

ANDERSON, Terence, "Visualization tools and argument schemes: a question of standpoint", Law, Probability and Risk n⿳0 6 (2007), pp. 97-107.

ANDRÉS IBAÑEZ, Perfecto, "Presunción de inocencia y prisión sin condena", Cuadernos de Derecho Judicial no 18 (1996), pp. 13-46.

, "Sobre el valor de la inmediación. (Una aproximación crítica)", Revista Jueces Para la Democracia n 46 (2003), pp. 57-66.

BAYON, Juan Carlos, "Epistemología, moral y prueba de los hechos: hacia un enfoque no benthamiano", ponencia presentada en el XIV Congreso ítalo-español de Teoría del Derecho [disponible en internet: http://www.udg.edu/LinkClick.aspx?fileticket=fYVRM58p9Z4\%3D\&tabid=9724\&la nguage $=$ en-US], p. 4.

BLANCO, Rafael et al, Litigación estratégica en el nuevo proceso penal, Santiago: LexisNexis, 2005, pp. 68-69.

CALVO, José "Hechos difíciles y razonamiento probatorio (Sobre la prueba de los hechos disipados)", Anuario de filosofía del Derecho no 18 (2001), pp. 13-34.

CARNELUTTI, Francesco, La prueba civil, Argentina: Ediciones Depalma, 1947, pp. 2930.

CARNEVALI, Raúl; CASTILLO, Ignacio, "El estándar de convicción de la duda razonable en el proceso penal chileno, en particular la relevancia del voto disidente", Revista Ius et Praxis, año 17, no 2 (2011), p. 83.

CASTRO, Javier, Introducción al Derecho procesal penal chileno, Santiago: LexisNexis, 2008, p. 282.

CLERMONT, Kevin; SHERWIN, Emily, “Comparative View of Standards of Proof”, The American Journal of Comparative Law, Vol. 50, $\mathrm{n}^{\mathrm{o}} 2$ (2002), p. 251.

COLOMA, Rodrigo, "Panorama General de la Prueba en el Juicio Oral Chileno", en: EL MISMO (Coord.), La Prueba en el Nuevo Proceso Penal Oral, Santiago: LexisNexis, 2004, p. 26.

, "Estándares de Prueba y Juicios por Violaciones a los Derechos Humanos", Revista de Derecho (Valdivia), vol. XXII, n² 2, (2009), pp. 205-229. 
BELTRÁN, Ramón. "Estándares de prueba y su aplicación sobre el elemento material de la prisión preventiva en Chile".

DUCE, Mauricio; RIEGO, Cristian, La Prisión Preventiva en Chile: Análisis de los Cambios Legales y su Impacto, Santiago: Ediciones UDP, 2011, pp. 34 y ss.

Chile, 2007, p. 252

, Proceso Penal, Santiago: Editorial Jurídica de

DURAN, Mario, "Justificación y legitimación político-criminal de la pena. Concepto, criterios y orientaciones en la actual jurisprudencia nacional", Política Criminal n ${ }^{\circ} 8$ (2009), pp. 1-24.

ENGEL, Christoph, "Preponderance of the Evidence Versus Intime Conviction: A Behavioral Perspective on a Conflict Between American and Continental European Law", Vermont Law Review, Vol. 33 (2009), pp. 435-467.

ETCHEVERRY, Alfredo, "Consideraciones sobre el criterio de condena en el código procesal penal”, en RODRÍGUEZ, Luis (Coord.), Delito, pena y proceso. Libro homenaje a la memoria del profesor Tito Solari Peralta, Santiago: Editorial Jurídica de Chile, 2008, pp. 659-678.

FERNÁNDEZ, Mercedes, Prueba y Presunción de inocencia, Madrid: Iustel. Portal Derecho S.A., 2005, pp. 117-159. , "La valoración de la pruebas personales y el estándar de la duda razonable", Cuadernos electrónicos de filosofía del derecho n ${ }^{\circ} 15$ (2007), pp.1-12.

FERRAJOLI, Luigi, Derecho y razón. Teoría del Garantismo Penal. Trad. Perfecto Andrés Ibañez et al, Madrid: Trotta, 1995, pp. 555 y ss.

FERRER, Jordi, "El contexto de la decisión sobre los hechos probados en el Derecho", en: ORTEGA, Santiago (ed.), Proceso, prueba y estándar, Lima: ARA Editores, 2009, p. 55.

, "Los estándares de prueba en el proceso penal español”, Cuadernos electrónicos de filosofía del derecho $\mathrm{n}^{\mathrm{o}} 15$ (2007), p. 6. , La valoración racional de la prueba, Barcelona: Marcial Pons, 2008, p. 146.

GASCÓN, Marina, "Sobre la posibilidad de formular estándares de prueba objetivos", Revista Doxa no 28 (2005), p. 20.

HAMER, David, "The Civil Standard of Proof Uncertainty: Probability, Belief and Justice", The Sydney Law Review, vol. 16 (1994), pp. 506-536.

HASSEMER, Winfried, "Los presupuestos de la prisión preventiva", en: DEL MISMO, Crítica al Derecho Penal de Hoy. Normas, Interpretación, Procedimiento. Limites a la Prisión Preventiva. Trad. Patricia S. Ziffer. Buenos Aires: Ad-Hoc, 2003, pp. 103 y ss.

HEMPEL, Carl, Filosofía de la Ciencia Natural, Trad. Alfredo Deaño. Madrid: Grupo Anaya Comercial, 2003, p. 58.

HORVITZ, Ma Inés; LÓPEZ, Julián, Derecho Procesal Penal Chileno, t. I, Santiago: Editorial Jurídica de Chile, 2003, pp. 401 y ss.

ITURRIALDE, Victoria, “Justificación judicial: Validez material y razones", Isegoría: Revista de filosofía moral y política $\mathrm{n}^{\mathrm{o}} 35$ (2006), pp. 207-220.

KINDHÄUSER, Urs, "Retribución de culpabilidad y pena", en: KINDHÄUSER, Urs; MAÑALICH, Juan Pablo, Pena y culpabilidad en el Estado democrático de Derecho. Trad. Nuria Pastor. Buenos Aires: ARA Editores, 2011, pp. 147 y ss.

KÜNSEMÜLLER, Carlos, "El Principio de Culpabilidad en el Derecho Penal Chileno", en: ARROYO, Luis; VERDUGO, Ignacio (Coords.), Homenaje al Dr. Marino Barbero 
Polít. crim. Vol. 7, No 14 (Diciembre 2012), Art. 6, pp. 454 - 479.

[http://www.politicacriminal.cl/Vol_07/n_14/Vol7N14A6.pdf]

Santos: "In memoriam", Vol. 1, Toledo: Ediciones de la Universidad Castilla-La Mancha / Ediciones Universidad Salamanca, 2001, pp. 1079-1098.

LAUDAN, Larry, "Por qué un estándar de prueba subjetivo y ambiguo no es un estándar", Revista Doxa $\mathrm{n}^{\mathrm{o}} 28$ (2005), pp. 96 y ss.

331.

LEONE, Giovanni, Tratado de derecho procesal Penal, Buenos Aires: El Foro, 1963, pp. 259 y ss.

LILLQUIST, Erik, "Recasting Reasonable Doubt: Decision Theory and the Virtues of variability", U. C. Davis Law Review no 36 (2002) pp. 185 y ss.

McBAINE, J.P., "Burdens of Proof: Degrees of Belief”, California Law Review, Vol. 32 (1944), pp. 262-263.

MAIER, Julio, Derecho procesal penal, Buenos Aires: Editores del Puerto, 1989, p. 258.

MENDONÇA, Daniel, Interpretación y aplicación del Derecho, Almería: Editorial Universidad de Almería, 1997, pp. 74 y ss.

, Las claves del Derecho, Barcelona: Editorial Gedisa, 2008, p. 196.

MORALES, Eduardo, Explicaciones de Derecho procesal, III: Derecho procesal penal, Santiago: edición privada, 1987, pp. 262-263.

MORESO, Juan José, La teoría del derecho de Bentham, Barcelona: Editorial PPU, 1992, pp. 354 y ss.

MULRINE, Thomas, "Reasonable doubt: how in the world it is defined?", American University International Law Review no 12 (1997), pp. 195-225.

PARDO, M. S. y ALLEN, R. J., "Juridical Proof and the Best Explanation", Law and Philosophy n 27 (2008), pp. 223-268.

PATTENDEN, Rosemary, "The risk of non-persuasion in civil trials: the case against a floating standard of proof", Civil Justice Quarterly no 7 (1989), pp. 220-233.

QUEZADA, José, Tratado de derecho procesal penal, Santiago: Ediar-Conosur 1994, pp. 253 y ss.

RIEGO, Cristián, "Nuevo estándar de Convicción”, Informe de Investigación nº17, año 5 (2003), p. 4.

ROXIN, Claus, Derecho procesal penal, Buenos Aires: Editores del Puerto, 2000, pp. 259 y ss.

SHAPIRO, Barbara, Beyond reasonable doubt and probable cause: Historical perspectives on the anglo-american law of evidence, Berkeley: University of California Press, 1991.

SOTO, Miguel, "Una Jurisprudencia Histórica: Hacia el Reconocimiento del Principio de Culpabilidad en el Derecho Penal Chileno", Revista de Derecho de la Universidad Finis Terrae, t. III (1999), pp. 233 y ss.

TARUFFO, Michele, "Senso comune, esperienza e scienza nel ragionamento del giudice", Rivista Trimestrale di Diritto e Procedura Civile no3 (2001) pp. 665-695.

, La prueba de los hechos. Trad. Jordi Ferrer Beltrán, Madrid: Trotta Editorial, 2009, p. 224.

, "Conocimiento científico y criterios de la prueba judicial", en: ORTEGA GOMERO, Santiago (ed.), Proceso, prueba y estándar. Lima: ARA Editores, 2009, pp. 43 y ss. 
BELTRÁN, Ramón. "Estándares de prueba y su aplicación sobre el elemento material de la prisión preventiva en Chile".

, La prueba, Trad. Laura Manríquez y Jordi Ferrer. Barcelona: Marcial Pons, 2008, p. 138.

, Simplemente La Verdad. El juez y la construcción de los hechos. Trad. Daniela Accatino. Barcelona: Marcial Pons, 2010, p. 99.

THAMAN, Stephen, "Detención y prisión provisional en los Estados Unidos", Cuadernos de Derecho Judicial n 18 (1996), Detención y prisión preventiva, pp. 193-226.

TWINING, William, "Rule-scepticism and Fact-scepticism in Bentham's Theory of Evidence", en: EL MISMO, Facts in Law, Wiesbaden: Franz Steiner, 1982, pp. 6581.

317-340.

WILLIAMS, C. R., "Burdens and Standards in Civil Litigation", The Sydney Law Review, vol. 25, no 2 (2003), pp. 165-188.

WHITMAN, James, The Origins of Reasonable Doubt: Theological Roots of the Criminal Trial, New Haven: Yale University Press, 2008, p. 3. 